Conselho Administrativo de Defesa Econômica Departamento de Estudos Econômicos

Documento de Trabalho $\mathrm{N}^{0} 005 / 2021$

\title{
Mensuração dos benefícios esperados da atuação do Cade em 2020
}

Guilherme Mendes Resende

(Economista-Chefe/Cade)

Thiago Luis dos Santos Pinto (Analista/Cade)

Nicole Chama dos Santos

(Chefe de Serviço/Cade) 


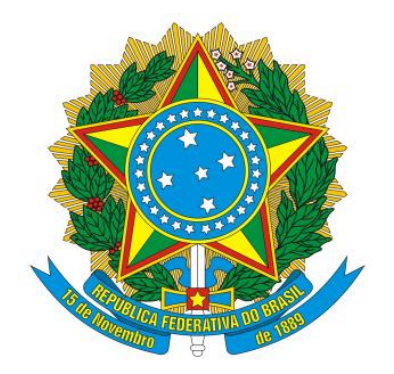

Ministério da Justiça e Segurança Pública Conselho Administrativo de Defesa Econômica

Mensuração dos benefícios esperados da atuação do Cade em 2020

Departamento de Estudos Econômicos - DEE

SEPN 515 Conjunto D, Lote 4, Ed. Carlos Taurisano

Cep: 70770-504 - Brasília-DF

www.gov.br/cade 
Este é um trabalho do Departamento de Estudos Econômicos (DEE).

\author{
O texto foi elaborado por \\ Guilherme Mendes Resende \\ (Economista-Chefe/Cade) \\ Thiago Luis dos Santos Pinto \\ (Analista/Cade) \\ Nicole Chama dos Santos \\ (Chefe de Serviço/Cade)
}

"As opiniões emitidas nos Documentos de Trabalho são de exclusiva e inteira responsabilidade do(s) autor(es), não exprimindo, necessariamente, o ponto de vista do Conselho Administrativo de Defesa Econômica ou do Ministério da Justiça e Segurança Pública."

"Ainda que este artigo represente trabalho preliminar, citação da fonte é requerida mesmo quando reproduzido parcialmente." 


\section{Sumário Executivo}

O presente Documento de Trabalho tem o objetivo de mensurar os benefícios esperados da atuação do Cade nos casos de conduta e atos de concentração decididos no ano de 2020. Dando sequência aos estudos referentes aos anos de 2018 e 2019, este trabalho se alinha com os esforços das autoridades antitrustes de estudar o impacto das suas ações e divulgá-los à sociedade.

Nesta edição do Documento de Trabalho, também são trazidas as informações dos benefícios obtidos da atuação do Cade de 2018, 2019 e 2020. De acordo com a recomendação da OCDE, a apresentação de uma média móvel dos últimos três anos dos benefícios mensurados "reduz a variabilidade das estimativas resultante de casos particulares de grandes e pequenos mercados, que pode acontecer em determinado ano". Dessa forma, sendo a 3a edição desse trabalho, a presente versão inaugura a mensuração deste cálculo, apresentando uma média de benefícios de $\mathrm{R} \$ 20,2$ bilhões ao longo dos últimos três anos.

Observando apenas o ano de 2020, estima-se que as ações do Cade tenham resultado em benefícios da ordem de $R \$$ 4,2 bilhões, decorrentes de decisões em casos de carteis, condutas unilaterais e atos de concentração nesse ano. Mesmo sendo inferior ao valor obtido em 2019 (de R\$ 37 bilhões, se corrigidos para dezembro de 2020), o benefício obtido em 2020 é significativo. Desses $R \$ 4,2$ bilhões, aproximadamente $R \$ 3,2$ bilhões se originaram da atuação do Cade nos casos de atos de concentração. Já as ações de combate às condutas anticompetitivas geraram $\mathrm{R} \$ 610$ milhões em benefícios nos casos de cartel e $\mathrm{R} \$ 401$ milhões nos casos de conduta unilateral.

É importante ressaltar o caráter conservador das estimativas apresentadas nesse estudo. Os valores apresentados não incorporam os efeitos dinâmicos das decisões ou os efeitos de dissuasão, nem incluem o impacto de determinadas ações promovidas pelo Cade (como atividades educativas e de promoção da cultura da livre concorrência). Além disso, os parâmetros adotados podem ser considerados conservadores quando comparados a outros trabalhos desse tipo. Essas observações reforçam ainda mais a relevância dos números obtidos.

Palavras-chave: Mensuração dos benefícios; Atos de concentração; Cartel; Conduta unilateral. 


\section{Sumário}

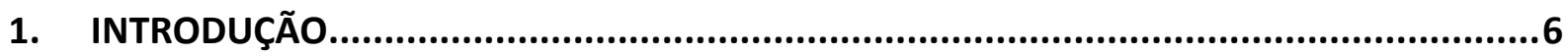

2. ANÁLISE DESCRITIVA DOS CASOS JULGADOS PELO CADE EM 2020 .............................7

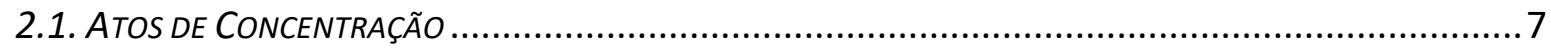

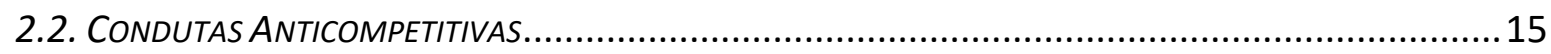

2.3. TERMO DE COMPROMISSO DE CESSAÇÃO (TCC) ……….................................................... 18

3. METODOLOGIA PARA QUANTIFICAÇÃO DOS IMPACTOS ESPERADOS ...........................19

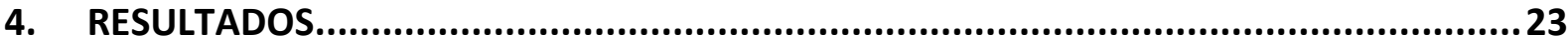

5. ANÁLISE DE SENSIBILIDADE



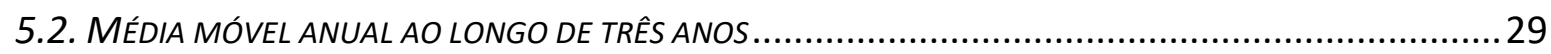

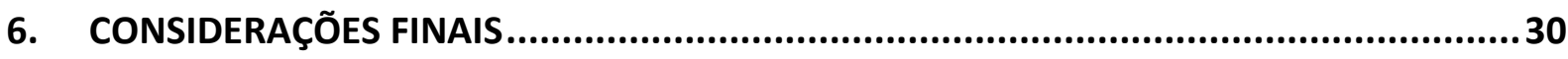

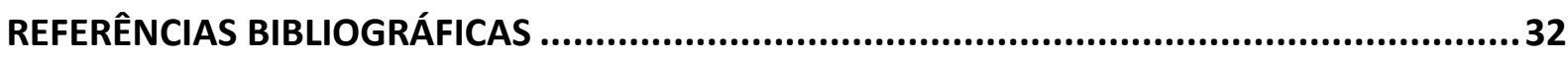

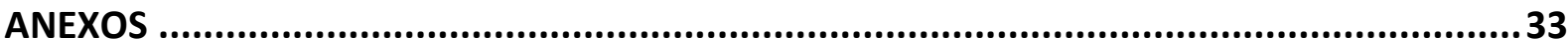




\section{Introdução}

Em 2020, o Departamento de Estudos Econômicos (DEE) publicou duas edições do Documento de Trabalho intitulado "Mensuração dos benefícios esperados da atuação do Cade", referentes aos anos de 2018 e $2019^{1}$. Com o intuito de dar continuidade ao trabalho e de dar transparência às atividades realizadas pelo órgão, nesta publicação serão estimados os benefícios da atuação da autarquia nos casos de condutas anticompetitivas e atos de concentração durante o ano de 2020.

Também nesta edição são trazidas as informações dos benefícios obtidos da atuação do Cade de 2018, 2019 e 2020. De acordo com a recomendação da OCDE, a apresentação de uma média móvel dos últimos três anos dos benefícios mensurados "reduz a variabilidade das estimativas resultante de casos particulares de grandes e pequenos mercados, que pode acontecer em determinado ano". Assim, por ser a 3a edição deste trabalho e contar, agora, com a base de dados necessária para início do cálculo da média móvel, a presente versão inaugura a apresentação deste cálculo.

Seguindo a mesma metodologia adotada nos trabalhos anteriores, as recomendações da OCDE são utilizadas como base para o desenvolvimento das estimativas apresentadas. Apenas para o ano de 2020, foram estimados $R \$ 4,2$ bilhões em benefícios originados da atuação do Cade. Esse valor é utilizado para se construir a média dos últimos três anos (2018, 2019 e 2020). Nesse sentido, é importante ressaltar que a estimativa de benefícios da atuação do Cade em 2020 mais apropriada é a média móvel dos últimos três anos que foi calculada em $\mathrm{R} \$ 20,2$ bilhões (no cenário recomendado pela OCDE).

Este trabalho é composto por seis seções. Além da presente introdução, a segunda seção apresenta uma análise descritiva dos casos julgados pelo Cade em 2020, com comentários sobre os principais deles. A terceira seção discorre sobre a metodologia adotada para o cálculo dos impactos esperados e discute as premissas adotadas. Na quarta seção são apresentadas as estimativas de benefícios, objeto principal deste trabalho, e na quinta seção são feitas análises da sensibilidade dos resultados obtidos aos parâmetros adotados incluindo o cálculo da média anual ao longo de três anos. Finalmente, a sexta seção apresenta as considerações finais.

\footnotetext{
${ }^{1}$ Ver Resende, Motta e Pinto (2020) e Resende e Pinto (2020).
} 


\section{Análise descritiva dos casos julgados pelo Cade em 2020}

\subsection{Atos de Concentração}

Em 2020 foram analisados 455 atos de concentração (AC) pelo Cade, sendo 424 aprovados sem restrições e 7 aprovados condicionados a assinatura de Acordo de Controle de Concentração (ACC). Dos 24 restantes, 2 foram arquivados por perda de objeto e 22 foram classificados como casos de "não conhecimento" ${ }^{2}$ e arquivados sem análise do mérito. Quando classificados quanto à abrangência geográfica, foram 364 casos de abrangência nacional e 91 de abrangência internacional. A Tabela 1 apresenta esses números.

\section{Tabela 1 - Atos de Concentração analisados em 2020, por Decisão}

\begin{tabular}{|c|c|c|c|c|c|}
\hline Abrangência & $\begin{array}{c}\text { Aprovado } \\
\text { sem } \\
\text { Restrição }\end{array}$ & $\begin{array}{c}\text { Aprovado } \\
\text { com } \\
\text { Restrição }\end{array}$ & $\begin{array}{c}\text { Não } \\
\text { conhecimento }\end{array}$ & Arquivado & Total \\
\hline Nacional & 338 & 7 & 18 & 1 & $\mathbf{3 6 4}$ \\
\hline Internacional & 86 & 0 & 4 & 1 & $\mathbf{9 1}$ \\
\hline Total & $\mathbf{4 2 4}$ & $\mathbf{7}$ & $\mathbf{2 2}$ & $\mathbf{2}$ & $\mathbf{4 5 5}$ \\
\hline
\end{tabular}

Fonte: Elaboração própria com dados do portal "Cade em Números".

Quanto ao rito, 391 dos 455 atos de concentração analisados foram julgados sumariamente (o que corresponde a $86 \%$ dos casos). Os 64 restantes ( $14 \%$ dos casos) cumpriram o rito ordinário.

Em seguida são analisados os 7 atos de concentração em que houve aprovação condicionada à assinatura de ACC. De acordo com as recomendações da OCDE (2014), são esses os casos em que há benefícios diretos decorrentes da atuação da autoridade antitruste, além dos atos de concentração reprovados. No entanto, ano de 2020 não houve casos de reprovação.

O primeiro caso, referente ao ato de concentração (AC) no 08700.001692/2019-46, celebrou uma aquisição de ativos pela empresa Brink's Segurança e Transporte de Valores Ltda. (“Brink's) da empresa Tecnoguarda Vigilância e Transporte de Valores Ltda. ("TecnoGuarda"). A operação ainda contou com o pedido de intervenção da empresa Tecnologia Bancária ("Tecban"), como terceira interessada no processo de ato de

\footnotetext{
${ }^{2}$ Casos de atos de concentração que estão fora dos requisitos exigidos pelo Cade para notificação, mas ainda assim são notificados pelas empresas.
} 
concentração. Todas as referidas acima trabalham no setor de prestação de serviços relativos ao transporte e custódia de valores.

O Grupo TecnoGuarda opera nos estados do Mato Grosso e de Goiás e o Grupo Brink's atua na maioria dos estados brasileiros. Nesse contexto, a dimensão do mercado relevante foi definida como estadual. O parecer da Superintendência-Geral (SG) revelou que a operação resultaria concentrações elevadas associadas a baixa rivalidade nos mercados de transporte e custódia de valores nos dois estados, principalmente Mato Grosso.

Assim, o Tribunal decidiu, em consonância com o que foi indicado pela SG, que o ato de concentração fosse aprovado sob um Acordo em Controle de Concentrações ("ACC"). O ACC deveria considerar as preocupações de ordem concorrencial levantadas ao longo do processo sobre: (i) os possíveis efeitos de natureza unilateral, no estado no Mato Grosso; e (ii) os possíveis efeitos coordenados, tanto no estado de Mato Grosso quanto em Goiás. Portanto, o ACC foi composto por remédios comportamentais, onde o Grupo Brink's se comprometeu a não participar em novos atos de concentração que envolvam outras empresas que ofertem os serviços de transporte e custódia de valores durante três (3) anos no Brasil, e manter o mesmo compromisso durante cinco (5) anos no estado do Mato Grosso.

O segundo ato de concentração, AC no 08700.002346/2019-85, se refere à aquisição de controle das empresas pertencentes ao Grupo São Bernardo pela Athena Saúde Espírito Santo Holding S.A. ("Athena ES"), ambas atuantes no setor de saúde do Estado do Espírito Santo. As requerentes alegaram que a operação permitiria uma ampliação de suas atividades, a perenidade das empresas do Grupo SBS e uma gestão mais eficiente dos serviços ofertados pela Athena ES. Com isso, ainda segundo as requerentes, o ato de concentração possibilitaria que o futuro grupo rivalizasse de maneira mais efetiva com o Grupo Unimed, então principal agente do setor de saúde suplementar no estado do Espírito Santo.

As investigações e análises realizadas pela Superintendência-Geral e pelo Departamento de Estudos Econômicos do Cade, porém, revelaram que a operação geraria preocupações concorrenciais no que tange a sobreposições horizontais entre as atividades das Requerentes nos seguintes mercados de planos de saúde: (i) individuais/familiares; (ii) coletivos por adesão; e (iii) coletivos empresariais no Estado do Espírito Santo. Além disso, geraria também integrações verticais quanto às atividades desenvolvidas pelos Grupo Athena ES e pelo Grupo SBS. 
Diante disso, o Tribunal, seguindo o voto do Conselheiro Relator (SEI 0771163), decidiu por aprovar o ato de concentração condicionado a um Acordo de Controle em Concentrações (ACC) contendo remédios estruturais e comportamentais, visando mitigar os riscos que a operação resultaria. De natureza estrutural, o ACC propôs a alienação de uma parcela da carteira de planos de saúde de coletivos empresariais das requerentes para uma OPS (Operadora de Planos de Saúde) concorrente. E de natureza comportamental, o ACC previu para as Requentes durante um período: (i) não aliciamento de empregados da operadora compradora; (ii) não concorrência; (iii) abertura e/ou manutenção da possibilidade de credenciamento dos Hospitais das Requerentes por operadoras de planos de saúde concorrentes; e (iv) notificação de atos de concentração nos mercados de planos de saúde no estado do Espírito Santo.

O terceiro caso - AC no 08700.001226/2020-02 - trata da aquisição de ativos da Boehringer Ingelheim International GMBH pela Hypera S/A. A Boehringer é uma empresa sediada na Alemanha e que atua mundialmente no desenvolvimento, fabricação, distribuição e comercialização de produtos farmacêuticos. A Hypera é uma empresa farmacêutica brasileira de capital aberto que está presente em todos os segmentos relevantes do setor, organizando seus negócios com as marcas Mantecorp Farmasa, Neo Química e produtos de Consumer Health Care, que inclui medicamentos isentos de prescrição (over-the-counter"OTC").

$O$ ato de concentração representaria, para a Boehringer, a finalização dos seus desinvestimentos de produtos de Consumer Health Care. Faltaria somente a liquidação dos produtos das marcas Buscopan (Buscopan, Buscoduo, Buscopan Composto e Buscofem), referentes aos medicamentos antiespasmódicos e analgésicos. A Hypera encara essa aquisição como um fortalecimento de sua posição no mercado de OTC com marcas que representam um alto potencial de crescimento no mercado farmacêutico brasileiro.

A Superintendência-Geral, no seu parecer (SEI 0772254), identificou os mercados relevantes da operação em dimensão nacional e em medicamentos antiespasmódicos e analgésicos (com classificações mais detalhadas). No entanto, tanto a SG quanto o Tribunal notaram que a operação cobrava atenção somente no mercado em que os medicamentos antiespasmódicos e analgésicos eram combinados (ATC3 e A3D). Isso porque a Hypera, que comercializava os medicamentos dessa classe da marca Neocopan Composto, ao adquirir os 
ativos da Boehringer da marca Buscopan que trariam consigo o Buscopan Composto e o Buscoduo, passaria a deter mais de $90 \%$ das vendas neste mercado.

Desse modo, o Tribunal decidiu (SEI 0788078) por celebrar um Acordo em Controle de Concentrações ("ACC") que garantia a alienação dos negócios da marca Neocopan Composto para a União Química (terceira interessada e que não possui em seu catálogo medicamentos que combinem antiespasmódicos com analgésicos), a fim de solucionar o problema concorrencial deste ato de concentração.

O quarto caso, AC no 08700.002592/2020-71, se trata da aquisição pelos Supermercados BH Comércio de Alimentos S.A. ("Supermercados BH") de 100\% da participação societária da empresa Comércio e Distribuição Sales Ltda. ("Supermercados Sales"). O Grupo Supermercados BH é uma rede de comércio varejista de gêneros alimentícios em geral, cuja estratégia de expansão no estado de Minas Gerais seria possibilitada pela Operação. Já o Supermercados Sales é uma sociedade empresária limitada também atuante no comércio varejista alimentício e no mercado de revenda em varejo de combustíveis. Para a empresa, a operação seria interessante uma vez que ela afirma que não possui mais interesse em atuar no ramo de supermercados e revenda de combustíveis no varejo.

A Superintendência-Geral, em seu parecer (SEI 0801161), identificou como mercados relevantes na dimensão produto o (i) mercado de revenda de combustíveis no varejo e o (ii) mercado de supermercados com 3 (três) ou mais check-outs (caixas), hipermercados e "atacarejos", excluídas mercearias, padarias e outros comércios de bairro. As preocupações concorrenciais centraram-se incialmente nas sobreposições horizontais encontradas no mercado relevante de supermercados nos raios dos municípios de Belo Horizonte, Contagem e Juiz de Fora, e nos municípios propriamente ditos de Carandaí e Conselheiro Lafaiete. No entanto, após analisar a rivalidade, a probabilidade de entrada e a probabilidade de exercício de poder de mercado das requerentes pós-operação, concluiu-se que o único desses municípios em que poderia haver efetivos problemas após a operação seria o de Carandaí.

Um Acordo de Controle de Concentrações foi então desenhado com um remédio estrutural de desinvestimento da Unidade de Negócios do município de Carandaí. A SG recomendou ao Tribunal a aprovação do ato de concentração condicionada à celebração do ACC proposto, e assim a operação foi aprovada. 
O AC no 08700.000627/2020-37 foi o quinto caso de ato de concentração aprovado com restrições, em 2020. Trata-se da aquisição de controle da Nike do Brasil Comércio e Participações Ltda. pelo Grupo SBF S.A. A Nike do Brasil, antes da operação, possuía a totalidade de suas cotas controladas pela Nike Galaxy Holding B.V. e Nike Group Holding B.V., e no Brasil atuava nos comércios varejista e atacadista de calçados, vestuário, acessórios e artigos esportivos. Já a SBF é uma holding de instituições não financeiras, e atua com o comércio varejista e atacadista de calçados e artigos esportivos. Segundo o relator do processo, o Grupo SBF é o responsável por controlar a SBF Comércio Ltda., a Lione Comércio de Artigos Esportivos Ltda. e a Premier Ltda.

Após o parecer da Superintendência-Geral (SEI 0792821) recomendar pela aprovação sem restrições do ato de concentração, o processo contou com recurso de uma terceira parte interessada, a empresa NS2.COM Internet S.A. ("Netshoes"). A empresa alegava que caso aprovado o ato de concentração, as requerentes teriam poder de fechamento de mercado em razão da capacidade de rivalidade da Nike frente a outras marcas, e reforçava quanto a sobreposição horizontal gerada no mercado de varejo de artigos esportivos com a aquisição do controle da Nike do Brasil pela Centauro, controlada do Grupo SBF.

Sendo assim, o Tribunal (SEI 0828559) decidiu por aprovar o ato de concentração condicionado a um Acordo de Controle de Concentrações que estabelecesse medidas comportamentais. Mesmo que a SG apontasse que as requerentes tinham capacidade, mas não incentivos ${ }^{3}$ para adotarem condutas anticompetitivas num cenário pós-operação, a integração vertical gerada à montante e à jusante nos mercados de distribuição de artigos esportivos e de calçados esportivos, respectivamente, ainda preocupava o relator do caso no Tribunal por dois motivos: (i) a prática da discriminação dos produtos Nike vendidos aos concorrentes da SBF/Centauro, no que tange a preço, quantidade e qualidade; e (ii) o uso de informações concorrencialmente sensíveis da Nike para definição de estratégias comerciais ou coordenação entre varejistas, por parte da SBF/Centauro.

Dessa forma, o ACC (SEI 0827184) buscou formalizar os mecanismos de desestímulo a condutas anticompetitivas por parte da nova companhia, através de medidas comportamentais que garantissem o tratamento isonômico e não-discriminatório por parte

\footnotetext{
${ }^{3}$ Pois poderiam sofrer retaliações de outras varejistas, como a diminuição da demanda pelos produtos da Nike, por exemplo.
} 
do Grupo SBF aos clientes da Nike do Brasil. As medidas contavam com (i) a separação das unidades de negócio da Centauro e da Nike do Brasil, a fim de garantir a confidencialidade das informações concorrencialmente sensíveis e a prestação de serviço dos colaboradores; (ii) um canal de denúncias, por onde a SBF receberia de terceiros e de colaboradores denúncias de práticas anticompetitivas, devendo reportar a Central and South America (que faz parte do Grupo Nike) e implementar mecanismos de supervisão; (iii) obrigações do Grupo Nike de assegurar isonomia e não-discriminação na distribuição dos seus produtos; além de, claro, monitoramento, prazos e multas em caso de não cumprimento do Acordo estabelecido no ato da aprovação da operação.

O ato de concentração no 08700.000827/2020-90 foi o sexto caso de aprovação com restrições julgado no ano de 2020. Este processo foi referente a uma operação celebrada entre a Copagaz Distribuidora de Gás, empresa nacional que atua na distribuição de gás liquefeito de petróleo (GLP), e a Itaúsa - Itaú Investimentos S.A., conglomerado brasileiro com participação e controle em diversos empreendimentos e empresas. Ambas notificaram a operação com o objetivo de adquirir os ativos da Liquigás Distribuidora S.A., empresa brasileira que atua com a distribuição de GLP envasado, a granel e propelente, além de ser atual líder de mercado desse segmento. A Liquigás integrava o Sistema Petrobrás e, portanto, era controlada pela Petróleo Brasileiro S.A.

Devido ao histórico preocupante no âmbito concorrencial, com a reprovação do ato de concentração entre a Ultragaz e a Liquigás em 2018, as requerentes preferiram notificar a presente operação já com uma proposta de fix-it-first, ou seja, com uma solução dos possíveis problemas concorrenciais que a concentração poderia gerar já nos estágios iniciais ou durante a apreciação do órgão antitruste. O remédio proposto pelas requerentes consistia no envolvimento de mais duas empresas no processo, a Nacional Gás Butano Distribuidora Ltda., empresa brasileira que atua com a distribuição do GLP envasado e a granel, e a Sociedade Fogás Ltda., também atuante no ramo de distribuição de GLP envasado e a granel, principalmente no norte do país. Para remediar os prováveis danos concorrenciais da operação, as então quatro requerentes acordaram em realizar uma série de desinvestimentos e rearranjos societários entre as quatro empresas com a aquisição da Liquigás, o que tornou o processo complexo e configurou, para a SG, como uma análise de três atos de concentração simultâneos. 
O Tribunal se alinhou à Superintendência-Geral e identificou que o ato de concentração poderia trazer danos à concorrência, principalmente no que tange ao exercício de poder de mercado unilateral (práticas coordenadas) na distribuição de GLP envasado e a granel nas regiões Sudeste e Centro-Oeste do país, devido às relações societárias envolvidas. Dessa forma, o Acordo de Controle de Concentrações, além de acatar sugestões das requerentes, também previu (i) uma série de remédios estruturais compostos por desinvestimentos e rearranjos societários; (ii) monitoramento, fiscalização e acompanhamento quanto aos serviços prestados entre concorrentes no momento posterior à Operação, no que tange, principalmente a troca/introdução de botijões dos agentes; (iii) estabelecimento de prazos e condições para que as unidades segregadas passem a ser gerenciadas e operadas pelas adquirentes; além de (iv) multa diária, em caso de não cumprimento da cláusula de desinvestimento, a ser recolhida a favor do Fundo de Defesa dos Direitos Difusos. Ainda sobre a questão dos botijões, segundo o voto do Conselheiro-Relator do caso (SEI 0834575), o ACC também previa a "(...)implementação dos compromissos sobre vasilhames informados à ANP, garantindo a transferência e introdução de botijões no menor tempo possível para o regular funcionamento das atividades envolvendo os ativos desinvestidos." Assim, o ato de concentração recebeu sua aprovação condicionada a um Acordo de Controle de Concentrações.

E, por fim, o sétimo AC no 08700.001227/2020-49, que consiste na aquisição pela Prosegur Brasil Transportadora de Valores e Segurança S.A. ("Prosegur") de ativos pertencentes à empresa SACEL Serviços de Vigilância e Transporte de Valores-EIRELI ("SACEL"), como veículos blindados (carros-fortes). A Prosegur é uma empresa de origem espanhola e pertencente ao Grupo Prosegur. Está presente em diversos países e atua com a oferta de serviços de segurança privada. Já a SACEL é uma empresa fundada no Estado do Sergipe que atua no mercado de transporte de valores e vigilância patrimonial. A justificativa para o ato de concentração se pauta na pretensão da Prosegur em ampliar sua participação no estado do Sergipe, conforme informa o Parecer da Superintendência-Geral (SEI 0815593).

O processo ainda contou com a empresa Tecnologia Bancária S.A. ("Tecban") como terceira interessada, que atua na área de planejamento e desenvolvimento de tecnologia bancária e presta serviços para a implementação, operação, manutenção e integração da rede multibanco de postos de autoatendimento. A Tecban alegou preocupações concorrenciais com a concentração horizontal gerada pela operação, pois uma vez tendo sido cliente das 
requerentes, chegou a interromper sua relação comercial em razão do "exercício abusivo de posição dominante" por parte da Prosegur, como descreve o parecer da SG. Além disso, a terceira interessada também aponta que como meio de lidar com o ato de concentração Prosegur-SACEL que ocorreu antes da notificação ao Cade ${ }^{4}$, ela promoveu a entrada da TBForte Segurança e Transporte de Valores Ltda. no mercado de transporte de valores no Sergipe, também para atender às próprias demandas e como emergência em virtude da saída da SACEL do mercado.

A SG identificou o mercado relevante sob a ótica do produto como sendo o mercado de transporte e custódia de valores, com as atividades de transporte de numerários, bens e valores, além de serviços de tesouraria. Quanto à delimitação geográfica, definiu o estado do Sergipe como um todo, onde a empresa Requerente SACEL atua. A possível eliminação da franja do mercado, com baixa rivalidade e exercício de poder de mercado coordenado, foram as preocupações concorrenciais consideradas pela autarquia e apontadas pela terceira parte interessada no processo.

Diante disso, o Tribunal, alinhado com a SG, decidiu por aprovar o ato de concentração condicionado a um Acordo de Controle de Concentrações. Como o ato já havia sido consumado quando da notificação ao Cade, a autarquia entendeu que os remédios estruturais não seriam pertinentes. Desse modo, tendo em vista a série de atos de concentração que vêm acontecendo no mercado de transporte e custódia de valores, a proposta do ACC foi de um remédio comportamental que proíbe a ocorrência de atos de concentração nesse mercado durante 3 anos para os Estados da Paraíba e Rio Grande do Norte e 4 anos para os Estados de Sergipe, Alagoas, Bahia e Pernambuco. A extensão geográfica constante no ACC foi mais ampla que o mercado relevante geográfico definido ao longo do processo, pois segundo a Conselheira Relatora é importante que se proteja a franja de mercado nas localidades próximas ao ato de concentração.

\footnotetext{
${ }^{4}$ A operação não foi notificada ao Cade previamente, porque não se enquadrava nos critérios de notificação obrigatória estabelecidos na Lei no 12.529/2011. Contudo, a operação foi notificada em atendimento à decisão proferida pelo Tribunal do Cade no Procedimento Administrativo de Apuração de Ato de Concentração no 08700.005079/2019-06, que assim decidiu com base no § 7으, do art. 88 da mesma Lei que dispõe: "É facultado ao Cade, no prazo de 1 (um) ano a contar da respectiva data de consumação, requerer a submissão dos atos de concentração que não se enquadrem no disposto neste artigo."
} 


\subsection{Condutas Anticompetitivas}

Em 2020, foram julgados pelo Cade 17 casos de conduta anticompetitiva, dos quais em 11 houve condenação, sendo os 6 restantes arquivados. Desses 17 casos, 13 se referem a casos de cartel, 2 de conduta unilateral e 2 de conduta comercial uniforme.

Os 11 casos de condutas anticompetitivas em que houve condenação das empresas investigadas encontram-se listados na Tabela 2. Dentre os 11 casos condenados, apenas 2 eram de abrangência internacional, sendo o restante de abrangência nacional. Um total de aproximadamente $\mathrm{R} \$ 138,5$ milhões foi aplicado em multas nessas 11 condenações. Destaque para os 4 primeiros casos, que, de forma exemplificativa, serão detalhados a seguir, que juntos correspondem a aproximadamente $88 \%$ desse total arrecadado em multas. É importante destacar também que em 2 deles houve a formalização de acordos de leniência (processos no 08012.003970/2010-10 e no 08700.001422/2017-73).

Tabela 2 - Casos de Condutas com Condenação em 2020

\begin{tabular}{|c|c|c|c|}
\hline Número do Processo & Conduta & Mercado & Multa (R\$) \\
\hline 08012.009732/2008-01 & Cartel & $\begin{array}{l}\text { Licitações municipais } \\
\text { referentes à aquisição } \\
\text { de equipamentos e } \\
\text { móveis de saúde }\end{array}$ & $55.446 .871,48$ \\
\hline 08012.007011/2006-97 & Cartel & $\begin{array}{l}\text { Prestação de serviços } \\
\text { médico-hospitalares }\end{array}$ & $27.563 .850,26$ \\
\hline 08012.003970/2010-10 & Cartel & $\begin{array}{l}\text { Cabos subterrâneos de } \\
\text { alta tensão e de cabos } \\
\text { submarinos de alta } \\
\text { tensão e de tensões } \\
\text { mais baixas }\end{array}$ & 20.964.914,93 \\
\hline $08700.001422 / 2017-73$ & Cartel & $\begin{array}{l}\text { Fornecimento de } \\
\text { forros, perfis e outros } \\
\text { produtos de PVC }\end{array}$ & $18.568 .537,15$ \\
\hline $08012.005009 / 2010-60$ & $\begin{array}{l}\text { Conduta } \\
\text { Unilateral }\end{array}$ & $\begin{array}{c}\text { Alarmes automotivos } \\
\text { no segmento } \\
\text { aftermarket }\end{array}$ & 7.994.733,09 \\
\hline 08012.003893/2009-64 & Cartel & $\begin{array}{l}\text { Prestação de serviços } \\
\text { anestesiológicos }\end{array}$ & $3.507 .887,17$ \\
\hline 08700.011474/2014-05 & Cartel & defensas marítimas & $2.793 .514,77$ \\
\hline 08700.005969/2018-29 & $\begin{array}{l}\text { Conduta } \\
\text { Comercial } \\
\text { Uniforme }\end{array}$ & $\begin{array}{c}\text { Proibição da aceitação } \\
\text { de cartões de }\end{array}$ & $900.000,00$ \\
\hline
\end{tabular}




\begin{tabular}{|c|c|c|c|}
\hline \multicolumn{4}{|c|}{$\begin{array}{l}\text { descontos pelos } \\
\text { médicos }\end{array}$} \\
\hline $08700.005615 / 2016-12$ & Cartel & $\begin{array}{l}\text { Licitação pública no } \\
\text { pregão de kits de } \\
\text { aquecedores solares } \\
\text { para habitações de } \\
\text { baixa renda }\end{array}$ & $534.860,83$ \\
\hline $08012.005069 / 2010-82$ & Cartel & $\begin{array}{l}\text { Compressores } \\
\text { herméticos para } \\
\text { refrigeração }\end{array}$ & $127.899,50$ \\
\hline 08700.010409/2015-43 & Cartel & $\begin{array}{l}\text { Licitações para } \\
\text { aquisição de } \\
\text { hemoderivados }\end{array}$ & $74.487,00$ \\
\hline & & Total & $138.477 .556,18$ \\
\hline
\end{tabular}

No primeiro caso, processo administrativo (PA) no 08012.009732/2008-01, o Tribunal do Cade condenou um total de 7 empresas e 2 pessoas físicas por formação de cartel em licitações públicas municipais referentes à aquisição de equipamentos e móveis de saúde Unidades Móveis de Saúde (UMS) e equipamentos médico-odontológicos-ocorridas em todo o Brasil. A SG, através de dados do Departamento Nacional de Auditoria do Sistema Único de Saúde do Ministério da Saúde ("Denasus") e do Tribunal de Contas da União ("TCU"), juntados através da Operação Sanguessuga, concluiu que 1.454 convênios foram impactados pela atuação do cartel durante os anos de 1999 a 2005. Nesse caso, foi aplicado um valor total de aproximadamente $\mathrm{R} \$ 55,5$ milhões em multas.

De acordo com os depoimentos colhidos pelo TCU, o cartel era organizado em três etapas: (i) na primeira obtinha-se a emenda parlamentar destinada à saúde, para fins de aquisição de UMS e equipamentos médico-hospitalares; (ii) na segunda elaborava-se préprojetos para a celebração do convênio junto ao Ministério da Saúde; e na (iii) terceira tratavase dos processos licitatórios. Como descreve a Nota Técnica da Superintendência-Geral (SEI 0240240), o cartel ocorreu em um esquema de fraudes licitatórias e atos de corrupção envolvendo, além das empresas, Deputados Federais, Prefeitos e servidores públicos da área da saúde. Os membros do conluio não só foram julgados por infração à ordem econômica no Cade, como também responderam processos pelos seus ilícitos penais à Lei de Licitações na Justiça Federal e no Tribunal de Contas da União, que objetivava apurar a responsabilidade de cada empresa envolvida no esquema licitatório. 
O segundo caso, referente ao PA no 08012.007011/2006-97, foi configurado pelo Tribunal do Cade como um cartel clássico entre empresas do mercado de prestação de serviços médico-hospitalares e plano de saúde na cidade de Fortaleza/CE. Em 2006, a Secretaria de Direito Econômico ("SDE") recebeu a denúncia da representante do caso, a HAPVIDA Assistência Médica Ltda., de que as representadas ${ }^{5}$ estariam supostamente infringindo a ordem econômica ao decidirem, conjuntamente, rescindir os contratos de prestação de serviço com a HAPVIDA. Além disso, também havia a tentativa unilateral de impor uma tabela de preços elaborada pelas empresas representadas à HAPVIDA, conforme a Nota Técnica no 20/2016/CGAA2/SGA1/SG/CADE (SEI 0207342).

A investigação da SG concluiu que as empresas representadas acordaram preços e serviços durante os anos de 2009 e 2012, prejudicando a livre concorrência e dominando o mercado relevante, nos termos do voto do Conselheiro Relator do caso (SEI 0793414). Diante disso, o Tribunal decidiu pela condenação de 10 representadas ${ }^{6}$ a pagar um total de multas de $R \$ 27,5$ milhões, e pelo arquivamento das 4 demais empresas ${ }^{7}$.

O terceiro caso (PA no 08012.003970/2010-10) teve início num Acordo de Leniência, intermediado pela Secretaria de Direito Econômico ("SDE"), firmado entre a União e duas empresas que confessaram envolvimento no cartel internacional - com efeitos no Brasil - de cabos subterrâneos de alta tensão e de cabos submarinos de alta tensão e tensões mais baixas (SEI 0635762). Ao longo da instrução do processo, outros representados firmaram Termos de Cessação de Conduta ("TCC") à medida em que eram entregues mais provas documentais que comprovaram a colusão existente nesse mercado. Após a conclusão das investigações, o

\footnotetext{
${ }^{5}$ Representadas: (i) Associação dos Hospitais do Estado do Ceará (AHECE), (ii) Clínica São Carlos Ltda, (iii) Otoclínica S/C Ltda, (iv) Hospital São Mateus S/C Ltda, (v) Hospital Geral e Maternidade Angeline, (vi) Wilka e Ponte Ltda (Hospital Gênesis), (vii) Casa de Saúde e Maternidade São Raimundo S/A, (viii) Hospital Cura D’ars Sociedade Beneficente São Camilo, (ix) Uniclinic - União das Clínicas do Ceará, (x) Hospital e Maternidade Gastroclínica - Clínica de Endoscopia e Cirurgia Digestiva Dr. Edgard Nadra Ary Ltda., (xi) Hospital Monte Klinikum, (xii) Sociedade de Assistência e Proteção à Infância de Fortaleza - SOPAl Hospital Infantil Luis França, (xiii) Instituto do Câncer do Ceará - ICC e (xiv) Luiz França Serviços Hospitalares Ltda.
}

${ }^{6}$ Condenação: (i) Associação dos Hospitais do Estado do Ceará (AHECE), (ii) Clínica São Carlos Ltda, (iii) Otoclínica S/C Ltda, (iv) Hospital São Mateus S/C Ltda, (v) Wilka e Ponte Ltda (Hospital Gênesis), (vi) Casa de Saúde e Maternidade São Raimundo S/A, (vii) Hospital Cura D’ars Sociedade Beneficente São Camilo, (viii) Uniclinic União das Clínicas do Ceará, (ix) Hospital e Maternidade Gastroclínica - Clínica de Endoscopia e Cirurgia Digestiva Dr. Edgard Nadra Ary Ltda. e (x) Instituto do Câncer do Ceará - ICC.

${ }^{7}$ Arquivamento: (i) Hospital Geral e Maternidade Angeline, (ii) Hospital Monte Klinikum, (iii) Sociedade de Assistência e Proteção à Infância de Fortaleza - SOPAI Hospital Infantil Luis França e (iv) Luiz França Serviços Hospitalares Ltda. 
Tribunal do Cade decidiu condenar 4 empresas e 3 pessoas físicas, aplicando um total de multas de aproximadamente $\mathrm{R} \$ 20,9$ milhões.

Por fim, o PA no 08700.001422/2017-73, que se refere a um cartel no mercado nacional de fornecimento de forros, perfis e outros produtos de PVC. A investigação, que se iniciou pela instauração de um inquérito administrativo na Superintendência-Geral em 2018, concluiu que “(..) havia troca de informações concorrencialmente sensíveis entre as empresas concorrentes com fins de reajuste de preços dos produtos, no mercado de forros e perfis de PVC, que incidiram em cartel difuso" (SEl 0672662). Ao longo da investigação, houve a formalização de um $\mathrm{TCC}^{8}$ com as partes representadas e de um Acordo de Leniência ${ }^{9}$.

Diante disso, o Tribunal decidiu pela condenação de 5 empresas e 2 pessoas físicas, aplicando um total de multas de $\mathrm{R} \$ 18,5$ milhões, e pela instauração de um novo processo administrativo para maiores apurações de participação na conduta anticompetitiva. Quanto aos demais representados, o processo foi arquivado ou por ausência de provas, ou por prescrição da pretensão punitiva.

\subsection{Termo de Compromisso de Cessação (TCC)}

Em 2020 foram homologados 17 Termos de Compromisso de Cessação (TCC), sendo 11 relativos a casos de cartéis, 4 relativos a condutas uniformes e outros 2 relativos a condutas unilaterais. Foram arrecadados aproximadamente $\mathrm{R} \$ 140,9$ milhões em contribuições pecuniárias com estes 17 termos.

Na Tabela 3 consta o total arrecadado em contribuições pecuniárias segundo o tipo de conduta. Os 11 casos de cartéis foram responsáveis pela maior parte da arrecadação $(R \$ 112,8$ milhões), seguidos pelos 4 de conduta uniforme ( $R \$ 3,3$ milhões) e pelos 2 de conduta unilateral ( $\mathrm{R} \$ 24,8$ milhões).

\footnotetext{
${ }^{8}$ Termo de Compromisso de Cessação de Tigre S.A. Tubos e Conexões (também referida como Tigre S/A Participações); Termo de Compromisso de Cessação de Paulo Roberto Cardozo.

${ }^{9}$ Celebração de Acordo de Leniência com relação os Representados BR Plásticos Indústria Ltda. e Lucilene Leschmann.
} 
Tabela 3 - Termos de Compromisso de Cessação (TCC) homologados em 2020, por conduta

\begin{tabular}{|l|c|cr|}
\multicolumn{1}{c|}{ Conduta } & Total & \multicolumn{2}{c|}{ Contribuições pecuniárias } \\
\hline Cartel & 11 & $\mathrm{R} \$$ & 112.823 .627 \\
\hline Conduta Uniforme & 4 & $\mathrm{R} \$$ & 3.250 .297 \\
\hline Conduta Unilateral & 2 & $\mathrm{R} \$$ & 24.832 .118 \\
\hline Total & 17 & $\mathrm{R} \$$ & 140.906 .042 \\
\hline
\end{tabular}

Fonte: Elaboração própria com dados do portal "Cade em Números".

Três casos se destacaram pelas maiores contribuições pecuniárias. O primeiro foi referente a um cartel no setor de obras de saneamento e infraestrutura hídrica, que originou uma contribuição de $\mathrm{R} \$ 46$ milhões. O segundo também é referente a um cartel, mas no mercado de produtos médicos e hospitalares, com uma contribuição de $\mathrm{R} \$ 32,8$ milhões. $\mathrm{E}$ por último um caso de conduta unilateral no mercado de serviços financeiros que gerou uma contribuição de $R \$ 23,9$ milhões.

É sempre importante ressaltar, entretanto, que esses valores não são suficientes para medir o impacto resultante das ações do Cade, como será visto na seção de resultados. Os benefícios esperados com a aplicação dos remédios nos casos específicos dos TCCs pdem superar expressivamente a arrecadação com as contribuições pecuniárias. Daí, portanto, a importância de se buscar a estimação desses benefícios com base na metodologia proposta pela OCDE (2014).

\section{Metodologia para quantificação dos impactos esperados}

A metodologia utilizada para quantificação dos impactos das ações do Cade segue basicamente as recomendações constantes na publicação "Guide for Helping Competition Authorities Assess the Expected Impact of Their Activities", desenvolvido e publicado pela OCDE, em 2014. Desde então, esse guia se tornou uma referência entre as autoridades antitrustes de todo o mundo para quantificar e divulgar os benefícios das suas respectivas ações.

Para estimar o impacto esperado das atividades da autoridade antitruste, o guia sugere uma metodologia que busca calcular o valor que seria gasto pelos consumidores caso as medidas dessa autoridade não tivessem sido adotadas. Na teoria econômica esse valor seria o equivalente ao somatório da perda de bem-estar de todos os consumidores em uma 
economia resultantes das distorções existentes. Assim, tal valor pode ser interpretado como o benefício gerado à sociedade em função da ação da autoridade antitruste.

De acordo com essa metodologia, o benefício ao consumidor gerado por uma decisão específica é dado pelo produto de três variáveis:

- O faturamento das empresas no mercado afetado;

- O sobrepreço removido ou evitado;

- A duração esperada do efeito sobre o preço.

Para determinar o valor de cada uma dessas variáveis foram utilizados os parâmetros recomendados pela OCDE, constantes na Tabela 4. Esses parâmetros são específicos para cada tipo de decisão (atos de concentração, cartéis e condutas). Somando os impactos de todas essas decisões obtém-se o impacto total da atuação da autoridade no ano estudado (no caso, o de 2020).

Tabela 4 - Parâmetros Recomendados pela OCDE

\begin{tabular}{|c|c|c|c|}
\hline & Receita das firmas envolvidas & Sobrepreço & Duração (anos) \\
\hline $\begin{array}{c}\text { Atos de } \\
\text { Concentração }\end{array}$ & $\begin{array}{l}\text { Receita de todas as firmas no } \\
\text { mercado afetado }\end{array}$ & $3 \%$ & 2 \\
\hline Cartel & Receita dos membros do cartel & $10 \%$ & 3 \\
\hline Conduta Unilateral & $\begin{array}{l}\text { Receita das companhias } \\
\text { investigadas }\end{array}$ & $5 \%$ & 3 \\
\hline
\end{tabular}

Fonte: Elaboração própria com dados da OCDE.

Nos atos de concentração, a OCDE (2014) recomenda que sejam considerados apenas casos nos quais haja reprovação da operação ou aprovação com imposição de remédios. Quando a concentração é aceita sem restrições, entende-se que não há interferência da autoridade e, assim, não se evita um dano ao consumidor. Logo, tais casos não são considerados na avaliação do impacto.

No ano de 2020 o Cade aprovou 7 atos de concentração com imposição de remédios. Nesses casos, foram considerados como mercados afetados apenas aqueles aos quais se destinam os remédios identificados nos respectivos ACCs. Ou seja, a receita de todas as firmas 
no mercado afetado de um determinado caso foi o somatório dos faturamentos de todas as firmas no mercado descrito no respectivo $\mathrm{ACC}^{10}$.

No entanto, nem sempre o somatório dos faturamentos de todas as firmas no mercado afetado esteve disponível. Quando isso ocorreu, buscou-se da melhor forma possível calcular uma proxy para esse somatório. Por exemplo, no AC № 08700.000827/2020-90, o faturamento do mercado afetado foi calculado com base numa estimativa para o preço do GLP por quilo em cada estado mencionado no ACC, uma vez que as informações ${ }^{11}$ sobre vendas só estavam disponíveis em quantidades (kg). Já no processo no 08700002346/201985, o faturamento total do mercado de planos de saúde coletivos empresariais foi estimado com base nos dados de participação de mercado e de faturamento com esses planos das empresas requerentes.

Além dos casos de atos de concentração, o guia da OCDE (2014) sugere que todas as decisões de condenação relativas a cartéis sejam consideradas no cálculo dos benefícios. No entanto, de acordo com as premissas conservadoras adotadas, casos em que pessoas físicas são condenadas não são contabilizados, uma vez que esses agentes não apresentam faturamento bruto oriundo de atividade econômica. Assim, dos 11 casos de conduta em que houve condenação, não foram considerados os 2 descritos a seguir:

(i) PA no 08700.010409/2015-43, que trata da condenação de uma pessoa física por cartel em licitações para aquisição de hemoderivados (investigação promovida pelo Ministério da Saúde na "Operação Vampiro");

(ii) PA no 08012.005069/2010-82, que trata da condenação de três pessoas físicas por formação de cartel no mercado de compressores herméticos para refrigeração, do PA Originário no 08012.00820/2009-11 (julgado em 2016).

\footnotetext{
${ }^{10} \mathrm{~A}$ metodologia da OCDE indica que se considere o faturamento total do mercado afetado. Por exemplo, no AC no 08700.002592/2020-71, as redes de supermercados envolvidas atuavam em diversos municípios do estado de Minas Gerais. Contudo, a análise do caso apontou problemas concorrenciais somente no município de Carandaí/MG, de forma que a intervenção prevista no ACC considerava somente esse mercado. Assim, na estimação de benefícios objeto deste documento de trabalho, considerou-se o faturamento do mercado de Carandaí/MG.

${ }^{11}$ Agência Nacional do Petróleo, Gás Natural e Biocombustíveis (ANP). Série Histórica do Levantamento de Preços. Série Histórica Mensal / A partir de 2013 / Estados. Disponível em: https://www.gov.br/anp/ptbr/assuntos/precos-e-defesa-da-concorrencia/precos/precos-revenda-e-de-distribuicao-combustiveis/seriehistorica-do-levantamento-de-precos.
} 
Também são excluídas do cálculo de benefícios entidades associativas que não apresentam faturamento, como associações, sindicatos, federações, etc.

Em relação ao período de análise, o guia recomenda que se considerem todos os julgamentos realizados ao longo do ano observado, atentando-se para que não haja dupla contagem dos benefícios. Nesse sentido, pode-se adotar a estratégia de considerar todas as sentenças, ainda que haja possibilidade de apelação, ou apenas incluí-las quando a decisão final for estabelecida. Optou-se pelo primeiro caso, isto é, foram consideradas todas as sentenças disponíveis no momento do desenvolvimento deste estudo.

Outra observação importante se refere às informações financeiras das empresas e à forma como foram tratadas. Procurou-se sempre utilizar as informações mais atuais possíveis. Quando não foi possível, os valores foram atualizados para dezembro de 2020 pela taxa Selic. Quando a informação disponível estava em moeda estrangeira, ela foi convertida para o Real pelo câmbio do último dia do ano ao qual se referia e depois atualizada para dezembro de 2020 pela taxa Selic.

Além das hipóteses de parâmetros, vale evidenciar que a principal hipótese utilizada nessa metodologia é a de que as políticas adotadas pela autoridade antitruste não têm efeito negativo sobre os consumidores. Adicionalmente, para todos os tipos de casos apresentados, não foram incluídos os efeitos dinâmicos das decisões sobre as economias ou ainda os efeitos de dissuasão. Isso reforça o caráter conservador das estimativas aqui apresentadas.

No que tange à divulgação dos resultados das análises, a OCDE (2014) sugere que os mesmos sejam reportados regularmente, de preferência anualmente, para reforçar o comprometimento com os resultados e a transparência. Sugere também a publicação dos resultados utilizando médias móveis, dividindo os valores ao longo de três anos. Essa medida visa internalizar o entendimento de que os efeitos não são observados apenas no ano da decisão, mas sim num período mais longo, especialmente para casos de maior magnitude. Recomenda também distinguir, sempre que possível, os resultados por tipo de decisão, em especial para os casos de cartel e atos de concentração. Ainda, propõe a realização de análises de sensibilidade sobre os parâmetros utilizados.

Por fim, cabe salientar que a avaliação de impactos esperados é conduzida logo após a tomada de decisão, quando ainda não se pode observar todos os resultados que essa decisão 
produziu. Dessa forma, esse tipo de avaliação difere da ex post, em que já é possível estimar os efeitos concretos das decisões.

\section{Resultados}

Nesta seção são apresentadas as estimativas de benefícios da atuação do Cade nos casos de conduta e atos de concentração de 2020. Essas estimativas foram obtidas considerando os parâmetros recomendados pela OCDE para receita, sobrepreço e duração (Tabela 4).

O impacto esperado total da atuação do Cade em 2020 foi de R\$ 4,2 bilhões (Tabela 5). Esse valor é inferior ao impacto estimado em 2019, que foi de $\mathrm{R} \$ 36$ bilhões (ou R\$ 37 bilhões, se corrigidos para dezembro de 2020). Embora seja uma redução considerável, ela já era esperada. Os números de 2019 foram bastante altos influenciados principalmente pelos TCCs assinados com a Petrobras, uma vez que o faturamento desta empresa é bastante alto. Logo, não era razoável esperar que os números de 2020 iriam se aproximar dos de 2019.

\section{Tabela 5 - Impacto esperado da atuação do Cade em 2020}

\begin{tabular}{|c|c|}
\hline Caso & Impacto esperado \\
\hline Cartel & $R \$ 610.968 .631$ \\
\hline Conduta Unilateral ${ }^{1}$ & $\mathrm{R} \$ 401.657 .783$ \\
\hline Ato de Concentração & $\mathrm{R} \$ 3.188 .437 .154$ \\
\hline Total & $R \$ 4.201 .063 .568$ \\
\hline
\end{tabular}

Fonte: Elaboração própria. (1) O total de conduta unilateral inclui os casos de conduta comercial uniforme

Ainda na Tabela 5 constam os impactos separados por cada tipo de atuação. Os casos envolvendo atos de concentração originaram a maior parte dos benefícios da atuação do Cade, tendo sido estimados em $\mathrm{R} \$ 3,2$ bilhões aproximadamente. Já nos casos de cartel, foram $\mathrm{R} \$ 610$ milhões os benefícios estimados. Por último, os casos de conduta unilateral geraram benefícios da ordem de aproximadamente R\$ 401 milhões.

A Tabela 6 apresenta os casos de cartel e conduta unilateral classificando-os quanto à existência ou não de um TCC (neste último caso, sendo conduzidos sob a forma de um processo administrativo (PA)). Ainda que sem a grande relevância verificada no ano de 2019, a contribuição dos TCCs na atuação do Cade em 2020 também é notória: aproximadamente 
$\mathrm{R} \$ 645$ milhões gerados em benefícios. Já os PAs responderam por aproximadamente $\mathrm{R} \$ 365$ milhões dos benefícios estimados.

Tabela 6 - Impacto esperado dos julgamentos dos casos de PA e TCC realizados pelo Cade em 2020

\begin{tabular}{|l|c|c|c|c|cr|}
\multicolumn{1}{|c|}{ Conduta } & \multicolumn{2}{c|}{ PA } & \multicolumn{2}{c|}{ TCC } & \multicolumn{2}{c|}{ Total } \\
\hline Cartel & R\$ & 278.299 .675 & R\$ & 332.668 .956 & R\$ & 610.968 .631 \\
\hline Conduta Unilateral & R\$ & 89.371 .162 & R\$ & 312.286 .621 & R\$ & 401.657 .783 \\
\hline Total & R\$ & $\mathbf{3 6 7 . 6 7 0 . 8 3 7}$ & R\$ & $\mathbf{6 4 4 . 9 5 5 . 5 7 7}$ & R\$ & $\mathbf{1 . 0 1 2 . 6 2 6 . 4 1 4}$ \\
\hline
\end{tabular}

Fonte: Elaboração própria.

\section{Análise de Sensibilidade}

Como já mencionado, as estimativas de benefícios apresentadas na seção anterior se baseiam nos parâmetros sugeridos pela OCDE. Na subseção 5.1, verifica-se o quanto essas estimativas são afetadas quando são alterados 2 dos 3 parâmetros utilizados: sobrepreço e duração. Em cada caso, é observado o efeito de se utilizar um parâmetro mais conservador e um mais agressivo em relação ao que é recomendado pela OCDE. O objetivo das simulações é ilustrar o quanto os benefícios se modificam quando são alterados esses 2 parâmetros simultaneamente. O terceiro parâmetro, a receita das empresas envolvidas, não é alterado basicamente porque é um dado, e não um número escolhido como os outros dois parâmetros.

A subseção 5.2 também apresenta o cálculo da média móvel anual, conforme recomendação da OCDE, que considera dados de três anos dos benefícios mensurados. De tal forma que este trabalho passou a ser publicado a partir de 2018 , esta é a terceira edição com o cálculo dos benefícios, o que permite calcular a média para os três anos - 2018, 2019 e 2020. Para tanto, também são considerados três cenários alternativos: Cenário 1, mais conservador; Cenário 2, de acordo com os parâmetros recomendados pela OCDE; e Cenário 3, menos conservador.

\subsection{Cenários para o ano 2020}

Em relação ao ano de 2020, a Figura 1 apresenta os níveis de benefícios obtidos com os atos de concentração quando o parâmetro de sobrepreço é alterado para um nível mais conservador (1\%) e para um menos conservador (5\%), e quando o parâmetro de duração é 
alterado para um nível mais conservador ( 1 ano) e para um menos conservador ( 3 anos). Quando se utiliza ambos no nível mais conservador (1\% e 1 ano), os benefícios obtidos são da ordem de R\$ 531 milhões, aproximadamente. Por outro lado, quando ambos são menos conservadores (5\% e 3 anos), os benefícios são de R\$ 8 bilhões, aproximadamente.

Figura 1 - Análise de sensibilidade dos parâmetros utilizados nos casos de atos de concentração em 2020

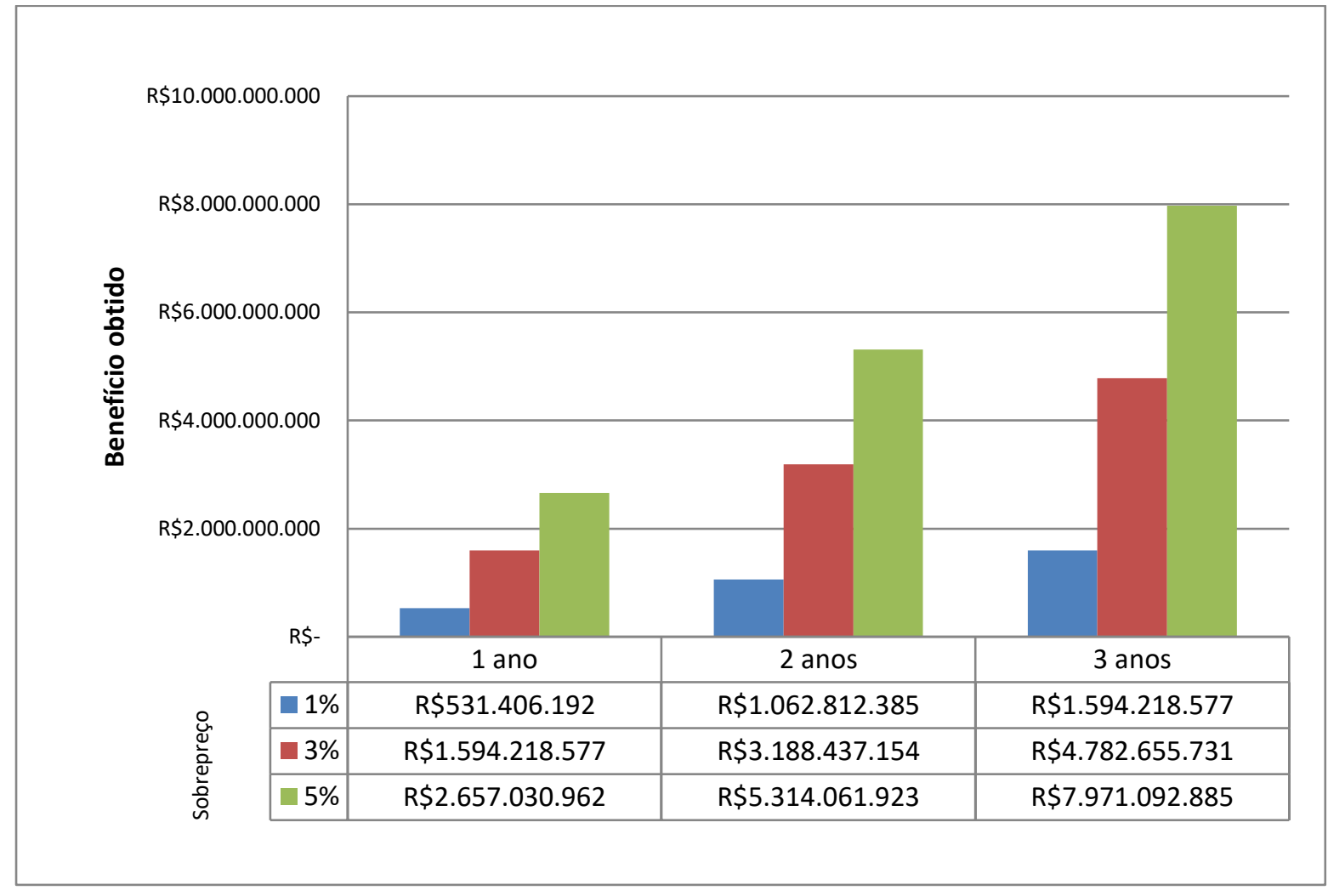

Fonte: Elaboração própria.

Em seguida, a Figura 2 ilustra os benefícios estimados nos casos de cartéis quando se altera o parâmetro de sobrepreço para um nível mais conservador $(5 \%)$ e para um menos conservador (15\%), e quando se altera o parâmetro de duração para um nível mais conservador (1 ano) e para um menos conservador (6 anos). Quando ambos são mais conservadores (5\% e 1 ano), obtém-se benefícios da ordem de $\mathrm{R} \$ 101$ milhões, aproximadamente. Por outro lado, utilizando ambos os parâmetros em níveis menos conservadores (15\% e 6 anos), obtém-se benefícios de R\$ 1,8 bilhão, aproximadamente. 


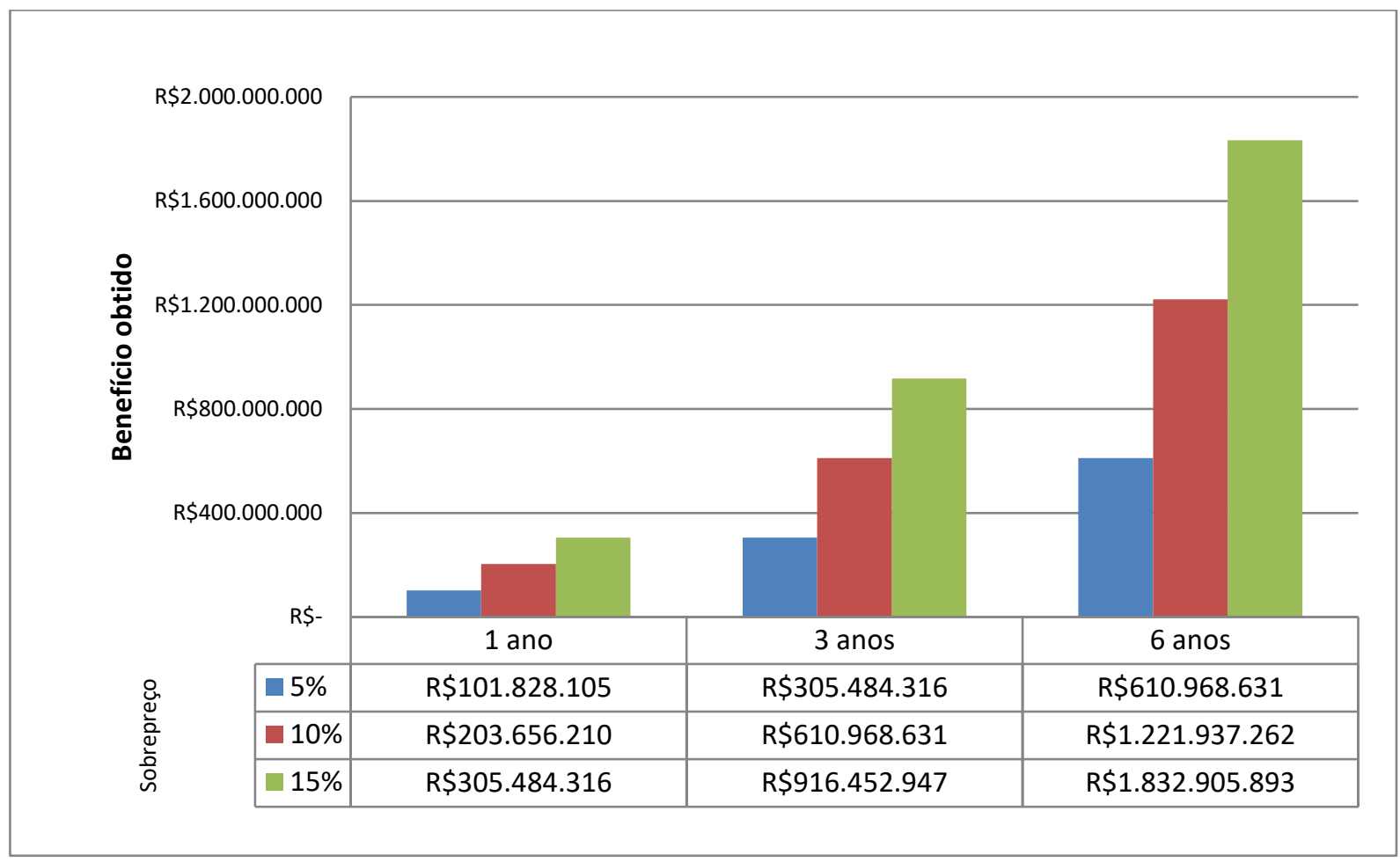

Fonte: Elaboração própria.

Finalmente, a Figura 3 mostra os níveis de benefícios obtidos nos casos de conduta unilateral quando se altera o parâmetro de sobrepreço para um nível mais conservador (1\%) e para um menos conservador (10\%), e quando se altera o parâmetro de duração para um nível mais conservador ( 1 ano) e para um menos conservador (6 anos). Quando ambos são mais conservadores ( $1 \%$ e 1 ano), obtém-se benefícios da ordem de R\$ 26 milhões, aproximadamente. Por outro lado, utilizando ambos os parâmetros em níveis menos conservadores (10\% e 6 anos), obtém-se benefícios de R\$ 1.6 bilhão, aproximadamente. 


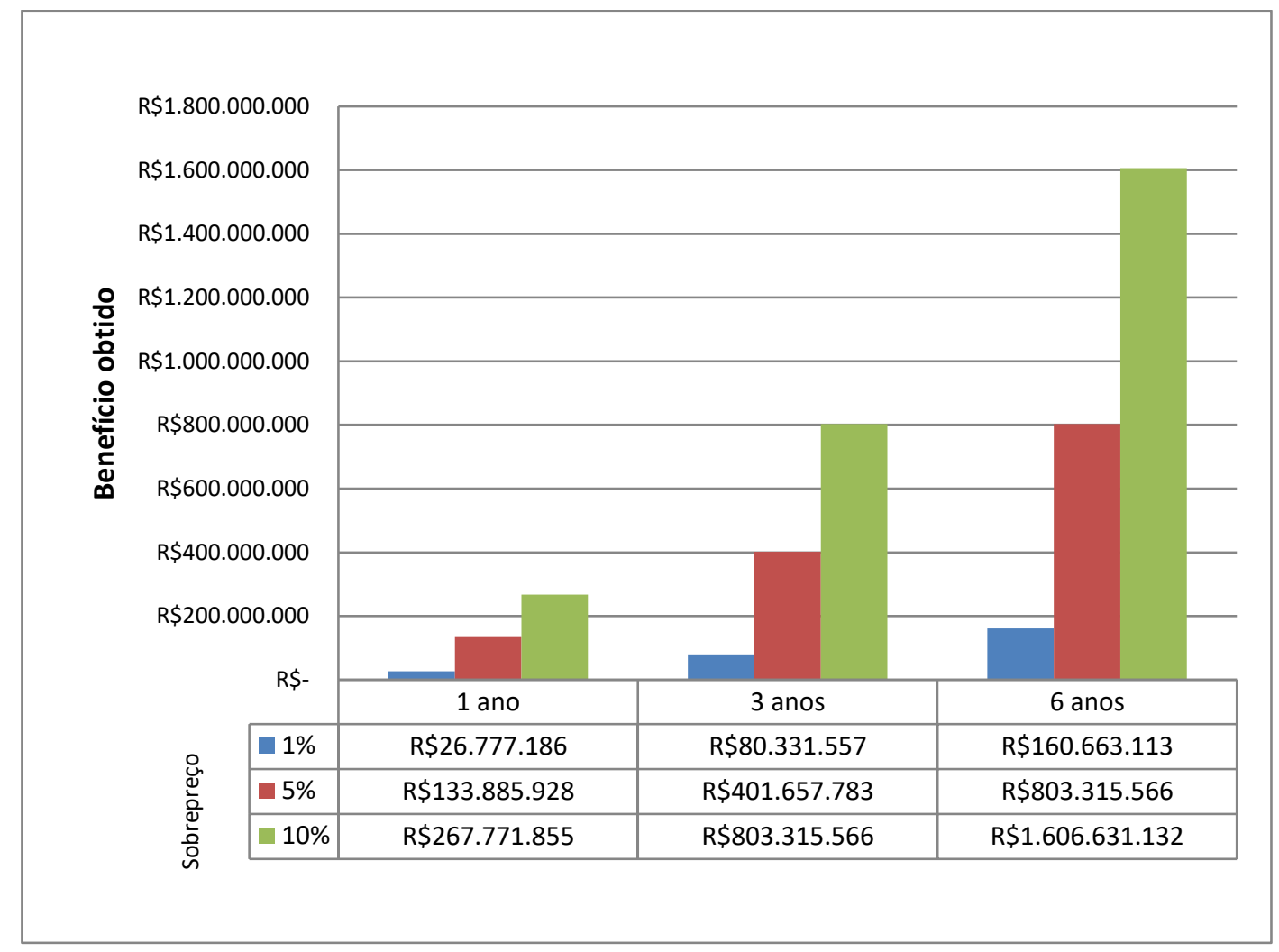

Fonte: Elaboração própria.

É importante destacar, mais uma vez, o conservadorismo das estimativas aqui apresentadas. Essas estimativas não incorporam diversos efeitos indiretos sobre as condutas anticompetitivas, como os efeitos dissuasivos ou efeitos dinâmicos. Além disso, os parâmetros aqui utilizados podem ser considerados conservadores se comparados aos adotados em outros trabalhos sobre o assunto, inclusive na literatura acadêmica.

Por último, é apresentado um comparativo dos benefícios obtidos quando os parâmetros de sobrepreço e duração são ambos escolhidos nos níveis mais conservadores (Cenário 1), nos níveis recomendados pela OCDE (Cenário 2) e nos níveis menos conservadores (Cenário 3). A Tabela 7 lista os parâmetros utilizados em cada cenário. 
Tabela 7 - Cenários para análise de sensibilidade conjunta

\begin{tabular}{|l|c|c|c|}
\hline \multicolumn{1}{|c|}{ Tipo de Caso } & Sobrepreço & Duração (Anos) & Cenário \\
\hline Cartel & $5 \%$ & 1 & Cenário 1 \\
\hline Conduta Unilateral & $1 \%$ & 1 & \\
\hline Ato de Concentração & $1 \%$ & 1 & Cenário 2 \\
\hline Cartel & $10 \%$ & 3 & \\
\hline Conduta Unilateral & $5 \%$ & 3 & Cenário 3 \\
\hline Ato de Concentração & $3 \%$ & 2 & \\
\hline Cartel & $15 \%$ & 6 & \\
\hline Conduta Unilateral & $10 \%$ & 6 & \\
\hline Ato de Concentração & $5 \%$ & 3 & \\
\hline
\end{tabular}

Fonte: Elaboração própria.

A Figura 4 simula os benefícios gerados pela atuação do Cade em cada um dos 3 cenários. No cenário 1, o mais conservador, o benefício obtido é de R\$ 660 milhões. Quando comparado com o cenário de parâmetros recomendados pela OCDE (cenário 2), que estima um benefício de cerca de $\mathrm{R} \$ 4,2$ bilhões, o cenário 1 representa uma redução de $84 \%$ deste benefício. Por outro lado, no cenário 3, o menos conservador, o benefício obtido é de $\mathrm{R} \$ 11,4$ bilhões, representando um acréscimo de $172 \%$ ao obtido com o cenário 2 .

Figura 4 - Análise de sensibilidade conjunta para o ano de 2020



Fonte: Elaboração própria. 


\subsection{Média móvel anual ao longo de três anos}

Em linha com as recomendações da OCDE, esse tópico busca apresentar a média anual ao longo de três anos. Conforme metodologia discutida ao longo deste trabalho, para cálculo dos benefícios esperados são considerados três cenários que diferem em níveis de sobrepreço e duração em anos. O Cenário 1 apresenta os benefícios da atuação do Cade em níveis mais conservadores; já o Cenário 2 considera as recomendações da OCDE, sendo também os parâmetros levados em conta pelo Cade para apresentar a mensuração dos benefícios de sua atuação; e por fim, o Cenário 3 é o menos conservador entre todos.

No Cenário 1, mais conservador, a média anual ao longo dos três anos foi de R\$ 2,1 bilhões. No Cenário 2, a média foi de $\mathrm{R} \$$ 20,2 bilhões, considerando os parâmetros mais recomendados pela OCDE. E no Cenário 3, a média anual dos benefícios mensurados foi de $\mathrm{R} \$$ 71,4 bilhões, de acordo com parâmetros menos conservadores. A Figura 5 abaixo ilustra o valor dos benefícios estimados para 2018, 2019 e 2020, e apresenta a média ao longo dos três anos para cada um dos três cenários.

Figura 5 - Média dos benefícios obtidos nos últimos 3 anos

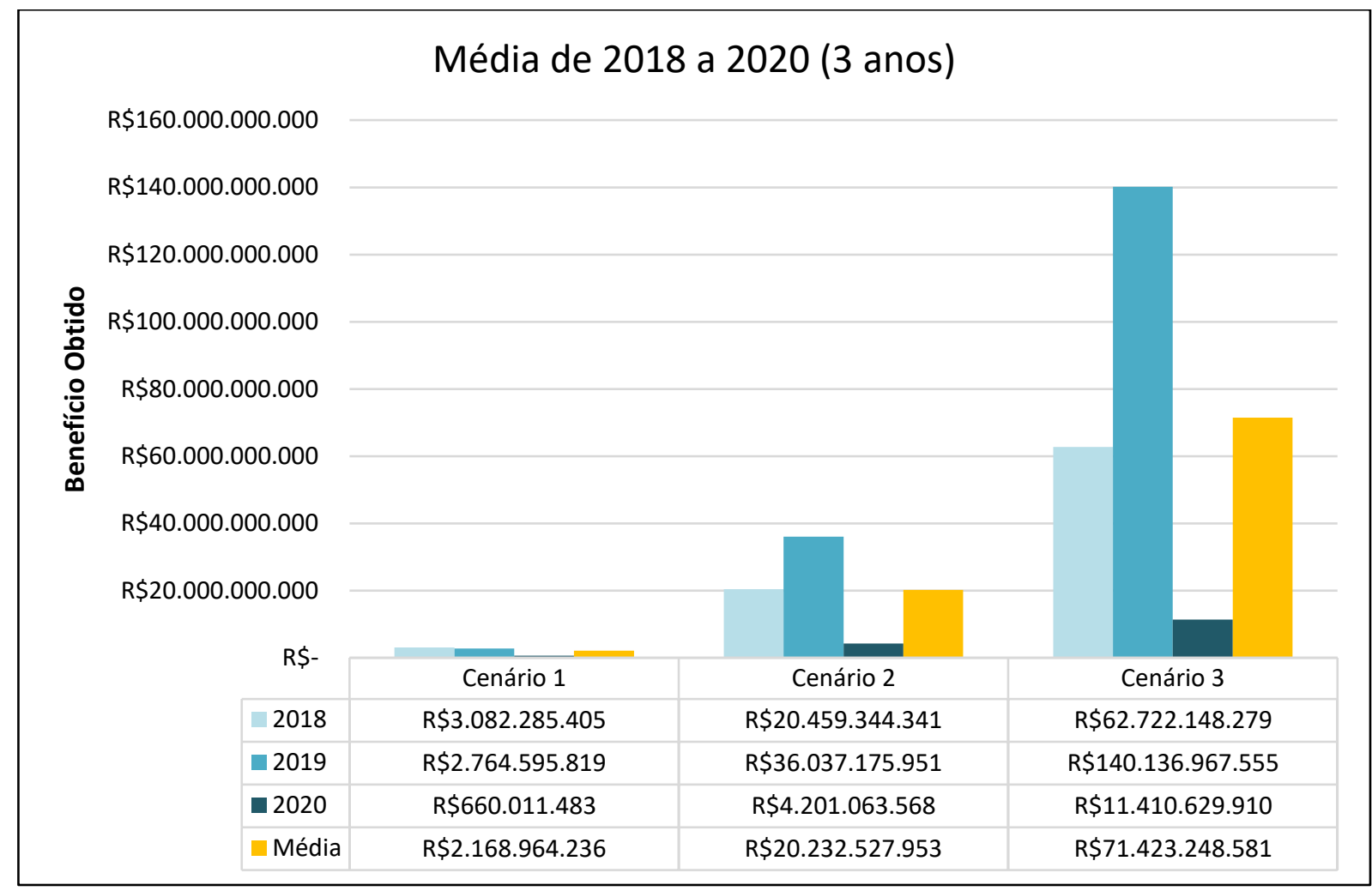

Fonte: Elaboração própria.

A comparação entre a média e os benefícios obtidos a cada ano, representados no gráfico acima, permite ilustrar exatamente o ponto que a OCDE faz em sua recomendação 
para o cálculo. O julgamento de casos que envolvam mercados muito grandes ou menores influencia diretamente no cálculo do benefício, e a média (móvel de três anos) busca balizar essa variabilidade nos resultados. Portanto, conforme discutido no presente documento, a partir do ano de 2020, a estimativa de benefícios da atuação do Cade mais apropriada é a média móvel dos últimos três anos que, para o ano de 2020, é de $\mathrm{R} \$ 20,2$ bilhões (no cenário recomendado pela OCDE).

\section{Considerações Finais}

Neste trabalho são apresentadas estimativas do impacto da atuação do Cade nos casos de conduta (cartel e conduta unilateral) e atos de concentração em 2020. Estima-se que essas ações tenham resultado na geração de benefícios da ordem de $R \$$ 4,2 bilhões. Esse pode ser considerado um número expressivo, embora inferior aos benefícios estimados nos anos de 2018 e 2019. Os números de 2019 foram bastante altos e influenciados principalmente pelos TCCs assinados com a Petrobras, uma vez que o faturamento desta empresa é elevado; já o valor estimado para 2018 tem grande participação das decisões sobre casos de cartel relacionados com a operação Lava Jato. Assim, compreensivelmente os números de 2020 foram inferiores aos dos 2 anos anteriores.

Destes $R \$$ 4,2 bilhões, aproximadamente $R \$ 3,2$ bilhões se originaram da atuação do Cade nos casos de atos de concentração. Ao longo de 2020 o Cade aprovou 7 atos de concentração condicionados ao cumprimento de remédios. Além disso, ao longo de 2020 o Cade julgou 11 casos de conduta anticompetitiva e negociou 17 Termos de Compromisso de Cessação. No total, foram estimados $\mathrm{R} \$ 610$ milhões em benefícios nos casos de cartel e R\$ 401 milhões nos casos de conduta unilateral.

Neste trabalho também foi apresentado, pela primeira vez, o cálculo da média dos benefícios obtidos ao longo de três anos - 2018, 2019 e 2020. Com isso pretende-se, a partir deste documento, publicar a média móvel para os últimos três anos a fim de, como recomendado no pela OCDE, reduzir a variabilidade do cálculo, resultante do julgamento de casos de grandes e pequenos mercados a cada ano. Portanto, para o ano de 2020, a estimativa de benefícios da atuação do Cade mais apropriada é a média móvel dos últimos três anos que foi calculada em $\mathrm{R} \$ 20,2$ bilhões (no cenário recomendado pela OCDE). 
Por fim, é importante ressaltar o caráter conservador das estimativas apresentadas nesse estudo. Os valores apresentados não incorporam os efeitos dinâmicos das decisões ou os efeitos de dissuasão, nem incluem o impacto de determinadas ações promovidas pelo Conselho (como atividades educativas e de promoção da cultura da livre concorrência). Além disso, os parâmetros adotados podem ser considerados conservadores quando comparados a outros trabalhos desse tipo. Essas observações reforçam ainda mais a relevância dos números obtidos. 


\section{Referências Bibliográficas}

Comissão Europeia (2015). Ex-Post Economic Evaluation of Competition Policy Enforcement: A Review of the Literature. http://ec.europa.eu/competition/publications/reports/ expost evaluation competition policy en.pdf

ICN (2013). Competition Enforcement and Consumer Welfare. International Competition Network ICN. http://www.internationalcompetitionnetwork.org/uploads/library/doc857.pdf

OECD (2014). Guide for helping competition authorities assess the expected impact of their activities. http://www.oecd.org/daf/competition/Guide-competition-impact-

assessmentEN.pdf

Resende, G. R.; Motta, L. V.; Pinto, T. L. S. (2019) Mensuração dos benefícios esperados da atuação do Cade em 2018. Documento de Trabalho no 1/2020, Conselho Administrativo de Defesa Econômica (Cade), Brasília. https://cdn.cade.gov.br/Portal/centrais-deconteudo/publicacoes/estudos-economicos/documentos-de-trabalho/2020/documento-detrabalho-n01-2020-mensuracao-dos-beneficios-esperados-da-atuacao-do-cade-em-2018.pdf

Resende, G. R.; Pinto, T. L. S. (2019) Mensuração dos benefícios esperados da atuação do Cade em 2019. Documento de Trabalho no 7/2020, Conselho Administrativo de Defesa Econômica (Cade), Brasília. https://cdn.cade.gov.br/Portal/centrais-de-conteudo/publicacoes/estudoseconomicos/documentos-de-trabalho/2020/documento-de-trabalho-n07-mensuracao-dosbeneficios-esperados-da-atuacao-do-cade-em-2019.pdf 


\section{Anexos}

Tabela A1 - Lista de TCC homologados pelo Cade em 2020

\begin{tabular}{|c|c|c|}
\hline Número do Processo & $\begin{array}{l}\text { Tipo de } \\
\text { Conduta }\end{array}$ & Mercado \\
\hline 08700.000714/2019-51 & Cartel & $\begin{array}{c}\text { Mercado nacional de produtos médicos e hospitalares, } \\
\text { incluindo órteses, próteses e materiais médicos } \\
\text { especiais (OPME). }\end{array}$ \\
\hline 08700.001092/2020-11 & Cartel & Mercado de peças automotivas. \\
\hline 08700.001940/2020-92 & Cartel & $\begin{array}{l}\text { Mercado de locação de equipamentos e veículos para } \\
\text { conservação, adequação e melhorias de estradas } \\
\text { rurais. }\end{array}$ \\
\hline 08700.002024/2019-36 & Cartel & $\begin{array}{c}\text { Mercado nacional de produtos médicos e hospitalares, } \\
\text { incluindo órteses, próteses e materiais médicos } \\
\text { especiais (OPME). }\end{array}$ \\
\hline 08700.002062/2019-99 & Cartel & Mercado internacional de capacitores. \\
\hline $08700.002160 / 2020-60$ & $\begin{array}{l}\text { Conduta } \\
\text { uniforme }\end{array}$ & $\begin{array}{c}\text { Mercado de prestação de serviços médicos de } \\
\text { coloproctologia, cirurgia oncológica e cirurgia do } \\
\text { aparelho digestivo. }\end{array}$ \\
\hline $08700.002174 / 2020-83$ & $\begin{array}{l}\text { Conduta } \\
\text { uniforme }\end{array}$ & $\begin{array}{l}\text { Mercado de prestação de serviços médicos de } \\
\text { cardiologia intervencionista. }\end{array}$ \\
\hline $08700.002176 / 2020-72$ & $\begin{array}{l}\text { Conduta } \\
\text { uniforme }\end{array}$ & $\begin{array}{l}\text { Mercado de prestação de serviços médicos de } \\
\text { angiologia, cirurgia vascular e endovascular. }\end{array}$ \\
\hline $08700.002351 / 2020-21$ & $\begin{array}{l}\text { Conduta } \\
\text { uniforme }\end{array}$ & $\begin{array}{l}\text { Mercado de prestação de serviços médicos de cirurgia } \\
\text { na coluna vertebral. }\end{array}$ \\
\hline 08700.003373/2019-75 & Cartel & $\begin{array}{l}\text { Mercado nacional e internacional de revestimentos de } \\
\text { embreagens. }\end{array}$ \\
\hline $08700.003425 / 2020-47$ & $\begin{array}{l}\text { Conduta } \\
\text { unilateral }\end{array}$ & Mercado de serviços financeiros. \\
\hline $08700.004137 / 2017-12$ & Cartel & Obras de saneamento e de infraestrutura hídrica. \\
\hline $08700.004408 / 2017-21$ & Cartel & Obras de saneamento e de infraestrutura hídrica. \\
\hline 08700.004419/2017-10 & Cartel & Obras de saneamento e de infraestrutura hídrica. \\
\hline
\end{tabular}




\begin{tabular}{|l|c|c|}
\hline $\mathbf{0 8 7 0 0 . 0 0 5 4 0 3 / 2 0 1 8 - 0 5}$ & Cartel & Mercado internacional de capacitores. \\
\hline $\mathbf{0 8 7 0 0 . 0 0 7 8 5 3 / 2 0 1 7 - 4 3}$ & $\begin{array}{c}\text { Conduta } \\
\text { unilateral }\end{array}$ & \begin{tabular}{c} 
Mercado de fornecimento de conexões de PP e PVC. \\
\hline $\mathbf{0 8 7 0 0 . 0 0 8 6 4 5 / 2 0 1 6 - 8 1}$
\end{tabular} \\
\hline & Cartel & $\begin{array}{c}\text { Serviços de engenharia para construção, ampliação e } \\
\text { reforma de portos e terminais aquaviários públicos no } \\
\text { Brasil. }\end{array}$ \\
\hline
\end{tabular}

Fonte: Elaboração dos autores com informações do Cade.

Tabela A2 - Tabela Resumo dos Casos de Atos de Concentração Analisados em2020

\begin{tabular}{|c|c|c|c|}
\hline Número do Processo & Teor da Decisão Geral & $\begin{array}{c}\text { Natureza } \\
\text { da } \\
\text { Operação }\end{array}$ & $\begin{array}{l}\text { Abrangência da } \\
\text { Operação }\end{array}$ \\
\hline 08700.001692/2019-46 & $\begin{array}{c}\text { Aprovação condicionada à celebração e } \\
\text { ao cumprimento de ACC }\end{array}$ & $\begin{array}{l}\text { Aquisição } \\
\text { de ativos }\end{array}$ & Nacional \\
\hline 08700.002346/2019-85 & $\begin{array}{c}\text { Aprovação condicionada à celebração e } \\
\text { ao cumprimento de ACC }\end{array}$ & $\begin{array}{l}\text { Aquisição } \\
\text { de controle }\end{array}$ & Nacional \\
\hline 08700.001226/2020-02 & $\begin{array}{c}\text { Aprovação condicionada à celebração e } \\
\text { ao cumprimento de ACC }\end{array}$ & $\begin{array}{l}\text { Aquisição } \\
\text { de ativos }\end{array}$ & Nacional \\
\hline 08700.002592/2020-71 & $\begin{array}{c}\text { Aprovação condicionada à celebração e } \\
\text { ao cumprimento de ACC }\end{array}$ & $\begin{array}{l}\text { Aquisição } \\
\text { de controle }\end{array}$ & Nacional \\
\hline $08700.000627 / 2020-37$ & $\begin{array}{c}\text { Aprovação condicionada à celebração e } \\
\text { ao cumprimento de ACC }\end{array}$ & $\begin{array}{l}\text { Aquisição } \\
\text { de controle }\end{array}$ & Nacional \\
\hline $08700.000827 / 2020-90$ & $\begin{array}{c}\text { Aprovação condicionada à celebração e } \\
\text { ao cumprimento de ACC }\end{array}$ & $\begin{array}{l}\text { Aquisição } \\
\text { de controle }\end{array}$ & Nacional \\
\hline $08700.001227 / 2020-49$ & $\begin{array}{c}\text { Aprovação condicionada à celebração e } \\
\text { ao cumprimento de ACC }\end{array}$ & $\begin{array}{l}\text { Aquisição } \\
\text { de ativos }\end{array}$ & Nacional \\
\hline
\end{tabular}

Fonte: Elaboração dos autores com informações do Cade.

Tabela A3 - Memória de Cálculo do Impacto Esperado em 2020

\begin{tabular}{|l|c|c|c|c|}
\hline \multicolumn{1}{|c|}{ Tipo de Caso } & Faturamento & Alíquota & $\begin{array}{c}\text { Duração Esperada } \\
\text { (Anos) }\end{array}$ & $\begin{array}{c}\text { Impacto Esperado } \\
\text { Total }\end{array}$ \\
\hline Cartel & R\$ 2.036.562.103 & $10 \%$ & 3 & $\mathrm{R} \$ 610.968 .631$ \\
\hline Conduta Unilateral & $\mathrm{R} \$ 2.677 .718 .554$ & $5 \%$ & 3 & $\mathrm{R} \$ 401.657 .783$ \\
\hline Ato de Concentração & $\mathrm{R} \$ 53.140 .619 .234$ & $3 \%$ & 2 & $\mathrm{R}$ 3.188.437.154 \\
\hline Total & $\mathbf{R} \mathbf{5 7 . 8 5 4 . 8 9 9 . 8 9 1}$ & & & $\mathbf{R} \mathbf{4 . 2 0 1 . 0 6 3 . 5 6 8}$ \\
\hline
\end{tabular}

Fonte: Elaboração dos autores com dados do Cade. 
Tabela A4 - Memória de Cálculo da Média dos Benefícios Obtidos nos últimos 3 anos

\begin{tabular}{|c|c|c|c|}
\hline Ano & Cenário 1 & Cenário 2 & Cenário 3 \\
\hline 2018 & $\mathrm{R} \$ 3.082 .285 .405$ & $\mathrm{R} \$ 20.459 .344 .341$ & $\mathrm{R} \$ 62.722 .148 .279$ \\
\hline 2019 & $R \$ 2.764 .595 .819$ & $\mathrm{R} \$ 36.037 .175 .951$ & $\mathrm{R} \$ 140.136 .967 .555$ \\
\hline 2020 & $\mathrm{R} \$ 660.011 .483$ & $\mathrm{R} \$ 4.201 .063 .568$ & $\mathrm{R} \$ 11.410 .629 .910$ \\
\hline Média & $\mathrm{R} \$ 2.168 .964 .236$ & $\mathrm{R} \$ 20.232 .527 .953$ & $\mathrm{R} \$ 71.423 .248 .581$ \\
\hline
\end{tabular}

Fonte: Elaboração dos autores com dados do Cade. 